УДК 621.31+330(77)

\title{
ЭНЕРГЕТИЧЕСКАЯ БЕЗОПАСНОСТЬ УКРАИНЫ: СОХРАНИЛСЯ ЛИ ЗАПАС ПРОЧНОСТИ?
}

\author{
А.А. Халатов, академик НАН Украины \\ Институт технической теплофизики НАН Украины,, ул. Желябова, 2а, Киев-57, 03057, Украина
}

Рівень енергетичної безпеки України визначається декількома показниками, кожен $з$ яких має індивідуальне порогове значення. Сьогодні значна частина цих показників знаходиться на межі між небезпечним і критичним станами.

Библ. 4.

\begin{abstract}
Уровень энергетической безопасности Украины определяется несколькими показателями, каждый из которых имеет индивидуальное пороговое значение. Сегодня большая часть этих показателей находится на границе между опасным и критическим состояниями.
\end{abstract}

The level of energy security of Ukraine is determined by several indicators, each of which has an individual threshold value. Currently most of these indicators are on the border between its dangerous and critical state.

Ключевые слова: энергетическая безопасность, топливная база, тепловая и атомная энергетика, газотранспортная система, энергоэффективность и энергосбережение.

\section{Введение}

Энергетическая безопасность страны является одной из важных составляющих ее экономической безопасности [1]. Она характеризует способность государственной системы в стабильных и нестабильных условиях обеспечивать население, промышленность и сельское хозяйство энергоносителями, тепловой и электрической энергией в объеме и качестве необходимыми для их устойчивого и надежного функционирования. С 1996 по 2011 г.г. интегральный показатель экономической безопасности Украины увеличивался с 49 \% до 60 \% (наивысший показатель в 2008-09 г.г.), но в дальнейшем наметилась устойчивая тенденция к его падению. Сегодня 7 из 10 показателей экономической безопасности страны находятся в опасной или критической зоне [1].

Оценка энергетической безопасности страны является сложной научно-технической проблемой и пока отсутствует унифицированная методика оценки ее состояния. В методике Организации Объединенных Наций $(\mathrm{OOH})$ и Международного агентства по атомной энергии (МАГАТЭ) для оценки энергетической безопасности используются 14 показателей (индикаторов), Мировой банк в своей методике использует 39 индикаторов, в Молдавии с учетом особенностей ее энергетики сформирована система из 24 показателей, а в Узбекистане используют только 4 показателя.

Методика расчета энергетической безопасности Министерства экономики Украины (2007) включает 9 показателей-индикаторов [1], которые сравниваются с установленными для них «пороговыми» значениями. Среди них - энергоемкость внутреннего валового продукта (ВВП) в [кг у.т. / грн], «пороговое» значение которой составляет $0,2 \ldots 0,5$; степень обеспеченности страны топливно-энергетическими ресурсами (ТЭР) (не менее $100 \%$ ); доля собственных источников в балансе ТЭР страны (не менее 50 \%); доля доминирующего топливного ресурса в ТЭР страны (не более $30 \%$ ); износ основных фондов предприятий топливно-энергетического комплекса (ТЭК) (не более 50 \%); доля инвести- ций в предприятия ТЭК по отношению к ВВП (3...4 \%); транзит природного газа (не менее 175 млрд. м $^{3}$ ) и нефти (не менее 56..65 млн. т), объем добычи угля (70...100 млн. т); доля импорта топлива из одной страны в общем объеме (не более 30 \%). Сегодня зависимость Украины от поставок энергоносителей из других стран составляет 65 \% (в Евросоюзе - 51 \%). Условием энергетической безопасности любой страны является поставка энергоносителей из 3-4 независимых стран.

В связи с серьезными изменениями, которые произошли в экономике, численности населения и политической жизни Украины в последние годы, показатели этой методики должны быть скорректированы.

Наивысший уровень энергетической безопасности (65 \%) Украина имела в 2008 г., хотя это ниже уровня устойчивой работы энергетического сектора $(80 \%)$. Cегодня уровень энергетической безопасности Украины, определяемый по методике [1], составляет около 50 \%, что находится на границе между опасным и критическим состоянием. Показатель научно-технического прогресса, характеризующий инновационные процессы в энергетике, также находится на границе между опасным и критическим уровнем.

\section{Топливная база энергетики}

Основным энергоносителем для тепловых электростанций (ТЭС) Украины является уголь. Подтвержденные запасы угля в Украине значительны, они составляют около 56 млрд. тонн, из которых $93 \%$ приходятся на Донецкий бассейн (6 место в мире), где главное место принадлежит антрациту (уголь марки А). Тепловые станции Украины используют уголь различных марок, однако 50 \% энергоблоков (7 из 14) суммарной установленной мощностью около 11 ГВт, используют только уголь марки А (антрацит) и Т (тощий уголь).

Еще в 2010 г. собственная обеспеченность углем энергетики Украины оценивалась на уровне 90 \%, что является высоким показателем. Военные действия на Юго-Востоке страны, которые начались в 2014 г., при- 
вели к существенным изменениям в структуре угледобывающей промышленности Украины. Если в 2012 г. в Украине добывали около 86 млн. тонн угля, то в 2014 г. добыто 65 млн. тонн угля, а в 2015 г. - около 40 млн. тонн. Это потребовало импорта энергетического угля в 2016 г. поставки из Луганской и Донецкой областей составили 6,8 млн. тонн, в 2016 г. - 9,2 млн. тонн. С начала 2017 г. по 15.03.2017 г. Украина получила из Луганской и Донецкой областей 1,7 млн. тонн угля антрацитовой группы (из ЮАР - только 39 тыс. тонн). Отметим, что примерно такое же количество антрацитового угля (1,7 млн. тонн) поступило из ЮАР за три года с 2014 по 2017 г.г. Прогнозы показывают, что в 2017 г. для ТЭС и ТЭЦ Украины необходимо 26,54 млн. тонн угля (импорт $-5,6$ млн тонн).

В 2011 г. Украина использовала 59,3 млрд. м³ природного газа в год, а собственная добыча составляла 14,5 млрд. м³. Оккупация Крыма привела к потере примерно 2,0 млрд. м ${ }^{3}$ газа ежегодно. В 2015 и 2016 г.г. собственная добыча газа составила 18 млрд. м $^{3}$, а его потребление снизилось до $33 \ldots 34$ млрд. м³. В настоящее время собственное потребление газа в Украине стабилизировалось на этом уровне. В 2015 г. около 16 млрд. м ${ }^{3}$ газа поступали из России и Европы; а в 2016 г. природный газ в Украину поступал из Европы по реверсной схеме $\left(11,1\right.$ млрд. м $\left.^{3}\right)$. В 2015 г. в связи с ростом цен и рядом ограничений потребление газа населением снизилось на $25 \%$, а промышленностью - на $22 \%$. Собственная добыча газа в Украине практически не растет по причине слабого финансирования работ по разведке и освоению новых месторождений.

В 2016 г. в Украине добыто 1 млн. 612 тыс. т нефти, что на $11 \%$ меньше чем в 2015 г., только за один год потребление нефти снизилось на 70,5\%. Сегодня в связи с недостатком нефти в Украине работает (да и то неустойчиво) только один Кременчугский нефтеперерабатывающий завод (НПЗ). В 2016 г. транзит нефти по территории Украины в Европу составил 13,82 млн. тонн, что на 8,8 \% меньше чем в 2015 г. В 2016 г. доля транзитного объема в транспортировке нефти составила 90,8 \%.

Таким образом, такие важные индикаторы как уровень собственной добычи энергоносителей, доля собственных источников в энергетическом балансе страны и доля транспорта энергоносителей в Европу не удовлетворяют условиям энергетической безопасности страны.

\section{Производство и потребление электроэнергии}

Основу электроэнергетики Украины составляют тепловые (ТЭС), атомные (АЭС), гидро- (ГЭС) и гидроаккумулирующие (ГАЭС) электростанции. Их суммарная установленная мощность составляет около 54 ГВт. В период с 2011 по 2013 г.г. производство электроэнергии в Украине практически стабилизировалось и в 2013 г. оно составляло 194 млрд. кВт. ч, т.е. чуть более 3500 кВт. ч на душу населения (56 место в мире). В 2014 г. вследствие событий на Юго-Востоке страны производство электроэнергии упало до 182 млрд. кВт. ч, в 2015 г. оно снизилось до 157,3 млрд. кВт. ч, а в 2016 г. - составило
157,7 млрд. кВт. ч. Тем не менее, в связи с сокращением населения Украины до 42,5 млн. (2017) годовое производство электроэнергии на душу населения возросло до 3700 кВТ. ч.

На тепловых электростанциях в 2013 г. было выработано 49 \% электроэнергии, а на атомных - 42,9\%. В 2015 и 2016 г.г. суммарная доля тепловой энергетики в общем объеме производства электроэнергии составила $35,2 \%$ и 36,5 \%, соответственно. Атомная энергетика в 2015 и 2016 г.г. работала в форсированном режиме, в этот период она выработала 55,6 \% и 52,3 \% электроэнергии, соотвтетственно.

С 2005 г. в Украине отмечается устойчивый рост потребления электроэнергии населением. В 2013 г. оно составило 28,1 \% от электроэнергии, произведенной в стране, а затраты коммунально-бытовых потребителей 12,6 \%. В 2015 г. потребление электроэнергии населением возросло до 30,6 \%, промышленность и коммунальнобытовые потребители использовали 42,4 \% и 12,8 \%, соответственно. С 2011 г. потребление электричества населением стало больше, чем в любой другой отрасли промышленности Украины, в том числе в металлургии.

Одной из главных проблем энергетики Украины является изношенность основных фондов производства, транспортирования и распределения электроэнергии, которая превышает 60 \% (в тепловой энергетике - 85 \%). Недостаток технически задействованных мощностей составляет 3..5 ГВт. Потери при транспортировании электроэнергии составляют $12 \ldots 16 \%$, что существенно выше европейской нормы (5..6\% \%).

\section{Тепловая энергетика}

Тепловая энергетика Украины (блоки 150, 200 и 300 МВт) создана в 60.. 70 г.г. ХХ в. и сегодня почти $85 \%$ ее мощностей превысили границу физического износа (200 тыс. час) [2, 4]. Среднегодовой коэффициент использования установленной мощности ТЭС Украины в 2013 г. составил только 31\% (мировой показатель - 40 \%, в США - более $60 \%$ ).

В настоящее время 26 блоков суммарной мощностью 6,7 ГВт эксплуатируются уже 200..250 тыс. часов (за пределами физического износа), 43 блока суммарной мощностью 10,4 ГВт - 250...300 тыс. часов, а 11 блоков мощностью 150 и 200 МВт (2 ГВт) превысили границу запредельного срока эксплуатации (300 тыс. часов). Значительно возросло количество аварийных остановок блоков (почти ежедневно), средний электрический КПД ТЭС Украины снизился до 29...31 \%, в то время как за рубежом лучшие энергоблоки докритического давления достигли КПД 40 \%, а КПД блоков сверхкритического давления находится в пределах $50 . .55 \%$. Хотя установленная мощность тепловой энергетики Украины составляет около 30 ГВт, но фактическая мощность в 2015 г. составляла только 21,8 ГВт, что обусловлено авариями, простоями и ремонтными работами, консервацией устаревшего оборудования.

До 2020 г. в Украине не планируется строительство новых энергоблоков, а только реконструкция с продлением сроков их эксплуатации на $15 . .20$ лет. Это снижа- 
ет финансовые затраты на поддержание тепловой энергетики в работоспособном состоянии (400...600 долл. США за 1 кВт установленной мощности), но не способствует ее коренной модернизации. К 2024 г. вследствие необходимости вывода из эксплуатации морально и физически устаревшего оборудования установленная мощность ТЭС может снизиться до 14 ГВт, к 2028 - до 12 ГВт и к 2033 г. - до 7,7 ГВт. К 2028 г. дефицит мощностей тепловой энергетики Украины может составить около 7 ГВт.

Удельные затраты условного топлива на ТЭС Украины велики и при работе ТЭС на антраците превышают 400 г условного топлива (у.т.) на производство 1 кВт·ч электроэнергии. По экологии ТЭС Украины не соответствуют европейским нормам. Показатели тепловых электростанций составляют 400...3200 мг/н м 3 по твердым частицам, 600...9000 мг/н м³ - по диоксиду серы и $400 \ldots 1600$ мг/н м ${ }^{3}$ - по оксидам азота. Тепловая энергетика Украины дает более 50 \% выбросов оксидов азота, более $60 \%$ оксидов серы и $30 \%$ твердых частиц. Украинские ТЭС не имеют сероочистки, выбросы двуокиси углерода от тепловой энергетики Украины составляют более 2,2 т на 1 человека в год.

Энергетика Украины работает в условиях неравномерного графика нагрузок. «Ночной провал» в 2012-13 г.г. составлял около 7 ГВт, который практически сохранился в 2015-16 г.г. Отсутствие маневровых мощностей в достаточном объеме приводит к необходимости использования тепловой энергетики в условиях переменной нагрузки, что отрицательно сказывается на эксплуатационной надежности энергетического оборудования и его более быстрому износу.

В 2014 г. в зоне Луганской и Донецкой обл. остались 4 тепловых электростанции общей установленной мощностью около 5 ГВт, что составляет 26,5 \% от технически задействованной мощности ТЭС Украины. В настоящее время возникла проблема, связанная с поставками угля антрацитовой группы из Донбасса (как указывалось выше, таких электростанций в Украине $50 \%$, их суммарная установленная мощность около 11 ГВт) поскольку украинские ТЭС спроектированы на использование угля Донецкого бассейна. Переход тепловых электростанций на использование угля марки Г (газовый) принципиально возможен, но сопряжен с большими финансовыми затратами. Средняя стоимость перевода блока ТЭС мощностью 200...300 МВт на уголь марки Г составляет около 10 млн. долл. США и занимает почти 2 года.

К сожалению, ЮАР, Австралия и Польша не в состоянии восполнить недостаток угля антрацитовой группы. По данным Министерства энергетики и угольной промышленности Украины в 2014-17 г.г. Украина закупила в ЮАР 1,75 млн. тонн угля антрацитовой группы, в то время как за этот период из Донецкого региона поступило 17,7 млн. тонн. Стоимость 1 тонны угля из ЮАР обошлась Украине в 3,1 тыс. грн., тогда как стоимость поставок из Донецкого региона составила 1,7 тыс. грн. Высокая стоимость импорта угля приводит к постоянному росту тарифов на электроэнергию для населения

\section{и промышленности.}

Состояние тепловой энергетики Украины находится в критическом состоянии, в ближайшие 8..10 лет следует ожидать снижения ее мощности. Подавляющее большинство блоков (85 \%) выработали границу физического износа (200 тыс. час), они характеризуются низким КПД, высокими удельными затратами топлива на производство единицы электрической энергии, большими выбросами вредных продуктов в окружающее пространство. Большие проблемы возникли с обеспечением ТЭС Украины углем антрацитовой группы, поставки угля из ЮАР и других стран не могут компенсировать поставки из Донецкого региона. Доля инвестиций в предприятия тепловой энергетики страны не способствует ее глубокой модернизации.

\section{Атомная энергетика}

Установленная мощность атомной энергетики Украины составляет 13,8 ГВт [2, 4]. В стране эксплуатируются 4 АЭС (15 блоков), в том числе самая большая в Европе Запорожская АЭС установленной мощностью 6 ГВт. В 2014-16 г. вследствие проблем в тепловой энергетике атомная энергетика Украины работала в форсированном режиме. Ее технически задействованная мощность была увеличена до 10,35 ГВт, а коэффициент использования установленной мощности возрос до 70 \% (в США - он составляет 90 \%). В 2013 г. на атомных станциях было выработано 42,9\%, а в 2015 и 2016 г.г. - 55,6 \% и 52,3\% электроэнергии. Ядерное топливо для АЭС практически полностью импортировалось из России.

Атомные блоки Украины близки к концу проектного срока эксплуатации (30 лет), в ближайшие 10 лет для 4 блоков он завершается. До 2025 г. из эксплуатации могут быть выведены 2 блока Южно-Украинской и 2 блока Ривненской АЭС, что снизит общую мощность АЭС Украины на 20 \%. К 2030 г. возникнет необходимость вывода из эксплуатации еще 5 блоков Запорожской, Южно-Украинской и Хмельницкой АЭС. Продление срока эксплуатации блоков АЭС на $15 \ldots 20$ лет (в США они работают до 60 лет) требует серьезного научно-технического обоснования и больших инвестиций. Продление срока эксплуатации только одного блока АЭС оценивается на уровне 100 млн. долл. США, а постройка нового блока - требует от 3 до 5 млрд. долл. США.

Атомная энергетика Украины обеспечивает сегодня более 50 \% производства электроэнергии. Сегодня важной проблемой атомной энергетики является научно-обоснованное продление еще на $10 \ldots 15$ лет безопасной работы ядерных реакторов и разработка программы строительства новых реакторов. Украина зависит от поставок ядерного топлива из России. Строительство в Украине завода по производству ядерного топлива задерживается из-за отсутствия необходимых средств.

\section{Гидроэнергетика}

Установленная мощность ГЭС и ГАЭС Украины составляет 5,5 ГВт [2, 4]. Одной из крупных является Днепровская ГЭС (1,57 ГВТ), а наиболее крупной ГАЭС Ташлыкская $(0,9$ ГВт). Особенностью их работы является высокая маневренность - их регулировочный ко- 
эффициент составляет $100 \%$, в то время как для ТЭС он равняется $20 \ldots 30 \%$, а для АЭС - только $10 \ldots 15 \%$. Поэтому наряду с выработкой электроэнергии ГЭС и ГАЭС широко используются для регулировки графика нагрузки электрической сети. Особенно важно наличие маневровых мощностей для устойчивой работы атомной энергетики, которая работает, главным образом, в базовом режиме.

Сегодня маневровые мощности энергосистемы Украины составляют только $9 \%$ от установленной мощности, в то время как минимально необходимый уровень в Европе составляет 20 \%. Агрегаты ГЭС и ГАЭС обеспечивают покрытие «пиковой» части суточного графика нагрузки только на $40 . .50 \%$, а остальная часть покрывается за счет работы ТЭС в маневровом режиме - с разгрузкой в ночное время (на $4 . .66$ часов) $12-15$ блоков зимой и 7-8 блоков - летом.

Энергосистеме Украины требуется около 15 ГВт маневровых мощностей, поэтому недавно Правительством Украины принята программа развития гидроэнергетики страны. В ближайшей перспективе планируется достроить Днестровскую и Ташлыкскую ГАЭС и построить Каневскую ГАЭС; тем не менее, дефицит «пиковой» мощности в Украине может сохраниться до конца 2030 г. В отличие от Европы Украина не использует для покрытия маневровых мощностей энергетические газовые турбины, которые обладают высоким коэффициентом маневренности (100\%), эксплуатационной надежностью, быстрым набором мощности и высоким КПД. Использование природного газа в качестве топлива не является ограничивающим фактором по причине высокой экономической эффективности газовых турбин.

Важная задача гидроэнергетики Украины - выравнивание суточного графика нагрузок энергосистемы. Сегодня мощности гидроэнергетики недостаточно для устойчивой работы энергетики страны и, прежде всего, атомной энергетики. Несмотря на планы развития гидроэнергетики Украины, недостаток маневровых мощностей сохранится до 2030 г. Поэтому необходимы дополнительные источники маневровых мощностей, такие как энергетические газовые турбины.

\section{Газотранспортная система}

Газотранспортная система Украины является самой большой в Европе [3], ее пропускная способность составляет более 280 млрд. м $^{3}$ газа в год, в том числе в Европу - около 180 млрд. м³. В 2011 г. в Европу было экспортировано 104 млрд. ${ }^{3}$ газа, а в 2015 г. - только 59 млрд. м³ , что связано с запуском двух ниток газопровода «Северный поток-1» пропускной способностью 55 млрд. м ${ }^{3}$ газа в год. В 2019 г. планируется запуск «Северного потока-2» такой же производительностью, что может существенно снизить поставки природного газа в Европу через Украину.

Сейчас обсуждается проект строительства двух ниток «Южного потока» производительностью 16 млрд. м ${ }^{3}$ в год каждая, одна из них предназначена для Турции, а другая - для европейских потребителей. Ввод в строй «Южного потока» в 2019 г. снизит транспорт газа че- рез Украину: к 2020 г. он может упасть до $10 \ldots 15$ млрд. м3, а доходы от транзита - уменьшатся на 2 млрд. долл. США.

Другой важной проблемой газотранспортной системы Украины является устарелое оборудование. Для привода компрессоров используются устарелые газотурбинные двигатели, средний коэффициент полезного действия которых составляет менее 30 \% [3]. При норме замены более 20 единиц ежегодно, заменяются только 2-3, по этой причине ежегодный расход природного газа в качестве топлива для газовых турбин составляет $2 . . .3$ млрд. ${ }^{3}$. Не проводятся работы по утилизации «выбросной» теплоты газовых турбин, технически возможный потенциал которой эквивалентен 2 ГВт. В ближайшие годы необходимо провести большие работы по модернизации морально и физически устарелых магистральных трубопроводов.

Один из важных показателей энергетической безопасности Украины транзит природного газа в Европу находится под серьезной угрозой. К 2019-2020 г.г. за счет строительства «обходных» газопроводов транзит газа через Украину может снизиться до 10...15 млрд. м3, а страна - потерять около 2 млрд. долл. США в год за счет транзита газа. В этом случае газотранспортная система Украины может оказаться в критическом состоянии.

\section{Энергоэффективность и энергосбережение}

Украина имеет один из самых высоких показателей потребления энергии на душу населения. При численности населения менее 1 \% от мировой, она потребляет более $2 \%$ мировых энергоресурсов (более 200 млн. тонн у.т. в год) и занимает 15 место среди крупнейших потребителей топливно-энергетических ресурсов. Сегодня Украина занимает первое место в Европе по энергозатратности валового продукта, которая в 3,5 раза выше, чем в промышленно развитых странах Европы и в 1,6 раза выше, чем в Беларуси $[2,4]$.

Наибольший потенциал экономии топлива сосредоточен в малой энергетике Украины, куда относятся промышленные ТЭЦ и котельные, коммунальная энергетика, промышленные печи, бытовые энергоустановки, автономные теплоцентрали. Они потребляют более $60 \%$ всего топлива в топливно-энергетическом комплексе Украины.

В Украине эксплуатируются большое количество низкоэффективных котельных и автономных генераторов теплоты, которые сжигают газ и мазут. Удельный расход топлива на производство тепловой энергии в них очень высок, а средний КПД не превышает $75 \%$, что ниже технически допустимого уровня. Эти источники тепловой энергии являются также основными источниками загрязнения окружающей среды. Украине необходимо снизить энергоемкость национального продукта до среднемирового уровня. Для этого необходимо:

1. Провести коренную модернизацию малых котлов и теплогенераторов, более широко внедрять котлы с высокими показателями КПД.

2. Выполнить реконструкцию части котельных с 
переводом их в более эффективные мини-ТЭЦ электрической мощностью до 50 МВт, что не требует крупных капиталовложений (1000...2000 долл. США на 1 кВТ установленной мощности). Срок окупаемости таких установок составляет $3 . .5$ лет, что в 2 раза меньше, чем в тепловой энергетике, а удельный расход топлива почти в 2 раза ниже, чем на мощных ТЭС.

3. Всемерно снижать потери энергоресурсов - тепловых потерь в теплотрассах при транспортировке тепловой энергии, электроэнергии в магистральных и распределительных электрических сетях.

4. Более широко использовать остаток «ночного провала» после ГАЭС (3...4 ГВТ) для целей теплоснабжения. Для этого могут быть использованы мощные тепловые насосы, а также накопительные системы электроотопления, которые будут играть роль потребителей-регуляторов для улучшения качества работы электрических сетей Украины.

5. Более широко использовать местные виды топлива, шахтный метан, биогаз бытовых отходов, котлы на торфе и биомассе.

6. Существенно снизить тепловые потери в зданиях за счет термомодернизации и использования новых теплоизолирующих материалов для строительной индустрии.

Рациональное использование топливно-энергетических ресурсов является одной из главных проблем Украины. Энергоемкость внутреннего валового продукта Украины в 2...2,5 раза выше, чем в ведущих странах Европы. Большой потенциал экономии топлива сосредоточен в малой энергетике Украины, которая потребляет более $60 \%$ всех топливно-энергетических ресурсов страны. Большие потери имеют место при транспортировке тепловой и электрической энергии, а также в жилищно-коммунальном хозяйстве Украины.

\section{Выводы}

- Энергетика Украины функционирует в сложных условиях, обусловленных нестабильной политической ситуацией в стране. Большая часть показателей энергетической безопасности страны находится на границе между опасным и критическим состоянием.
- Добыча угля - основного энергоносителя для электростанций Украины - в 2016 г. упала в 2 раза, проблемы в снабжении ТЭС Украины углем антрацитовой группы привели к кризисным явлениям в энергетике. Транзит природного газа в Европу существенно сократился и имеет устойчивую тенденцию к дальнейшему снижению, что может привести к деградации газотранспортной системы Украины.

- Тепловая энергетика Украины характеризуется низкими эксплуатационными характеристиками и значительными выбросами вредных продуктов в атмосферу. Около 85 \% ТЭС Украины выработали физический ресурс и морально устарели, поузловая модернизация в тепловой энергетике может продлить жизнь тепловой энергетики еще на $15 \ldots 20$ лет, но не способствует ее технической модернизации.

- Атомные блоки Украины приближаются к концу проектного срока эксплуатации. Первостепенными задачами являются разработка научно-обоснованной программы продления срока эксплуатации атомных блоков на $15 \ldots 20$ лет и разработка программы строительства новых реакторов.

- Большие задачи стоят в области энергоэффективности и энергосбережения, прежде всего, в области малой энергетики Украины, которая потребляет более 60 $\%$ топливных ресурсов страны.

\section{ЛИТЕРАТУРА}

1. Кваша I.M. Стан енергетичної безпеки України (оцінка та методологія розрахунку). В сб. «Загрози енергетичній безпеці України в умовах посилення конкуренції на глобальному та регіональному ринках енергетичних ресурсів». Київ: 2012.

2. Вольчин I.А., Дунаєвська Н.І., Гапонич Л.С., Чернявський M.B., Топал O.I., Засядько Я.I. Перспективи впровадження чистих вугільних технологій в енергетику України. Київ: Изд. ГНОЗИС, 2013. 319 с.

3. Халатов А.A., Карп I.M., Куцан Ю.Г. Енергетичне газотурбобудування: перспективи використання в енергетиці України. Вісник НАН України, 2015, №11.

4. Халатов A.A. Енергетика України: сучасний стан і найближчі перспективи. Вісник НАН України, 2016, №6. 


\section{THE ENERGY SAFETY OF UKRAINE: IS THERE A SAFETY MARGIN?}

\section{Khalatov A.A.}

Institute of Engineering Thermophysics of the National Academy of Sciences of Ukraine, vul. Zhelyabova, 2a, Kiev, 03580, Ukraine

The energy safety of Ukraine is determined by several indicators, the most important of which are the energy intensity of gross domestic product, degree of country security with its own fuel and energy resources, wear of basic assets of the fuel and energy complex, transit of energy resources the country, investments in the fuel and energy complex of Ukraine, and some others. The paper considers the infrastructure of energy and power sector of Ukraine, which includes the fuel base of energy and power engineering, thermal and nuclear engineering, hydropower engineering, and natural gas pipeline network. It is shown most indicators of energy security of Ukraine are on the border between its dangerous and critical state.

\section{References 4.}

Key words: energy safety, fuel base, thermal and nuclear power engineering, natural gas pipeline network, energy efficiency and energy safety.

1. Kvasha I.M. State of energy security of Ukraine (evaluation and methodology). Collection of papers «Threats of energy security of Ukraine in the face of increased competition in the global and regional markets for energy resources». Kyiv: 2012 [in Ukrainian].

2. Volchyn I.A., Dunaevska N.I., Haponich L.S., Chernyavskyi M.V., Topal O.I., Zasiadko Ya.I. Prospects for implementation of clean coal technologies in the energy sector of Ukraine. Kyiv: Gnozis, 2013, 319 p. [in Ukrainian].

3. Khalatov A.A., Karp I.N., Kutsan Yu.G. The power gas turbines: prospects of application in power engineering of Ukraine. Visnik NANU, 11, 2015 [in Ukrainian].

4. Khalatov A. Energy sector of Ukraine: modern state and nearest prospects. Visnik NANU, 6, 2016 [in Ukrainian].

Получено 21.03.2017

Received 21.03.2017 